\title{
Policy Review and Outlook on China's Sustainable Development since 1992
}

\author{
WANG Yi ${ }^{1,2}$, SUN Honglie ${ }^{3}$, ZHAO Jingzhu ${ }^{1,4}$ \\ (1. Research Center for Eco-Environmental Sciences, Chinese Academy of Sciences, Beijing 100085, China; 2. Institute of \\ Policy and Management, Chinese Academy of Sciences, Beijing 100190, China; 3. Institute of Geographic \\ Sciences and Natural Resources Research, Chinese Academy of Sciences, Beijing 100101, China; \\ 4. Institute of Urban Environment, Chinese Academy of Sciences, Xiamen 361021, China)
}

\begin{abstract}
The Road to Rio+20 is the journey of countries in the world pursuing the sustainable development. As the first country to release the national Agenda 21, China's experience and lessons are of great significance for both China itself and other countries. The paper reviews the progress made and problems remained in pursuing the sustainable development in China with regard to policy formulation, institutional arrangements, planning and management. In the past five years, the mandatory targets-driven approach, which focused on energy efficiency and key pollutants reduction, played a very important role and made China comprehensive outcomes for sustainability. In order to achieve the targets, China adopted an integrated policy package including legal, administrative, economic and technology instruments. During the 12th Five-Year Plan period (2011-2015), China will continue and strengthen the approach above and mainstream the transformation of economic development pattern through realizing the idea of green and low-carbon development. By summarizing policy trends in the world, the paper points out two directions, i.e., integration approach and taking prioritized and concrete actions for a sustainable future beyond 2012. The paper also presents policy approaches and recommendations for sustainable development in the next 10 years in China.
\end{abstract}

Keywords: sustainable development; policy review; experience; Rio+20; China;

Citation: Wang Yi, Sun Honglie, Zhao Jingzhu, 2012. Policy review and outlook on China's sustainable development since 1992. Chinese Geographical Science, 22(4): 381-389. doi: 10.1007/s11769-012-0518-0

\section{Sustainable Development: Milestone of Human Development and Constantly Evolving Development Framework}

\subsection{Progress of sustainable development in world and challenges it faces}

It is already 20 years since the concept of sustainable development was created. In 2012, the United Nations will hold a conference on sustainable development for summarizing the progress made in sustainable development since the United Nations Conference on Environment and Development (UNCED) in 1992 in Rio. This is a period in which humans have made constant progress in reviewing their own development. The World
Commission on Environment and Development (WCED), in its 1987 report 'Our Common Future', defined sustainable development as 'Development that meets the needs of the present without compromising the ability of future generations to meet their own needs' (WCED, 1987). This definition has remained a classic one, and this principle was universally accepted by more than 100 countries, including China, at the 1992 UNCED. The World Summit on Sustainable Development (WSSD) in 2002 made it clearer that the economic development, social development and environmental protection be three pillars of sustainable development at local, national, regional and global levels, which are interdependent and mutually reinforcing. Sustainable development stresses fairness, equity and integration of

Received date: 2011-05-23; accepted date: 2011-08-12

Foundation item: Under the auspices of Strategic Priority Research Program of Chinese Academy of Sciences (No. XDA05150300)

Corresponding author: WANG Yi. E-mail: wangyi@casipm.ac.cn

(C) Science Press, Northeast Institute of Geography and Agroecology, CAS and Springer-Verlag Berlin Heidelberg 2012 
the above-mentioned three pillars. It took poverty eradication, changing consumption and production patterns, and protecting and managing the natural resource base for economic and social development as the overarching objectives, and essential requirements for sustainable development (WSSD, 2002). Sustainable development is therefore realized as managing broader portfolio of assets to make them grow for long-term benefits (World Bank, 2003).

Over the past 20 years, we have, on the one hand, seen the progress made in sustainable development in the world, with the United States, Canada and European Union and other developed countries and regions as well as China and Brazil and other developing countries formulating their own sustainable development strategies and relevant policies, and on the other hand, we have also seen that, due to the lack of compulsory laws and standards, there has been limited substantial progress in sustainable development in some countries, especially developing countries with the overreaching objectives set hard to realize, thus making them unable to steer off the trajectory of non-sustainable development. In the meanwhile, most of developed countries have not fully honored their commitments to supporting developing countries in 2008 (UN, 2009). The conflicts between environment and development are exacerbating and it remains arduous to eradicate poverty. In United Nations Environment Programme's Global Environment Outlook (GEO), Environment for Development (GEO-4), which has been published recently, admits that the world has made progress only in tackling some relatively straightforward problems and the humanity is still facing unrivaled challenges by environmental changes (UNEP, 2007). Some experts even hold that the concept of sustainable development has fallen prey to a collection of special interest groups that have both hollowed out the concept and lost track of what they can best do to implement it. When it has been applied, the theory has often distorted the real priorities of development. The environmental issues have not been sufficiently mainstreamed in policymaking process in much of the world. If it recovered its original meaning, it is necessary to make a priority of alleviating poverty, dropping the environmental bias that has hijacked the entire movement, favoring local decisions over global ambitions, and tapping into new technologies to spur sustainable growth (Victor, 2006).

\subsection{Policy progress on sustainable development in China and new background for development}

China is one of the countries that were the earliest to get involved in the compiling of 'Our Common Future' and signed in 1992 the 'Rio Declaration' and 'Agenda 21'. In the following, the contents of some reports are referred (Compilation Group of the People's Republic of China National Report on Sustainable Development, 2002; Connor and Stephen, 2004; the State Council of the People's Republic of China, 2006; European Commission, 2007; Sustainable Development Strategy Research Group of the Chinese Academy of Sciences, 2006; 2008; 2009; 2010; 2011; AASA, 2011). In 1994, China was the first to issue the 'Agenda 21', China's Agenda 21-China White Paper on Population, Environment and Development in the 21st Century. In 1996, sustainable development was officially fixed as one of the basic development strategies. The concept of sustainable development has been turned from scientific consensus into an important part of government work and concrete action. The '10th Five-Year Plan' had set the goals of sustainable development in all areas for that period of time and the key special plans had been developed and implemented. Up to the present, China has formulated 30 laws in such areas as population, resources, energy and environment, including the 'Environmental Protection Law', the 'Water Law', the 'Cleaner Production Promotion Law', the 'Renewable Energy Law', and the 'Energy Conservation Law'. The State Council has formulated more than 100 administrative rules and regulations on sustainable development. In addition, there are several hundred regulations and standards worked out by government ministries and commissions. China has ratified or signed more than 50 multilateral environmental agreements and has made a series of institutional arrangements for implementing the sustainable development strategy. The Standing Committee of the National People's Congress has set up an Environmental and Resources Conservation Committee, which has played a major role in drafting laws and overseeing their enforcement and implementation.

Organizationally, in 1992 the Chinese government set up a leading group and its office for the compilation of 'China Agenda 21', which was led by the former State Planning Commission and the State Commission for Science and Technology. Then, it went on to set up the China Agenda 21 Management Center. In 2000, the 
'China Agenda 21' Compilation Leading Group was renamed as 'National Leading Group for Promoting Sustainable Development Strategy' to coordinate various departments and organize the implementation of projects. In 1998, the former National Environmental Protection Agency (NEPA) was elevated to the ministerial level to become the State Environmental Protection Administration (SEPA) with the enhanced administrative status and functions. At the same time, all government departments have been orderly advancing work relating to sustainable development. Despite the fact that sustainable development has unveiled a scene of clean, safe, just and more competitive and vigorous development, and in view of the great differences between issues and development context we are facing at present and what we were facing more than ten years ago, to realize sustainable development, we have to remove many threats that are present or are in the making, and the threats are as follows.

(1) China has entered the middle stage of industrialization marked by rapid development of heavy and chemical industries. The consumption structure has gradually been upgraded. China is experiencing an objective historical process featuring the intensification of resources and energy consumption and pollutants discharge. We are facing the dual pressure of how to seize the important strategic opportunities to rapidly realize industrialization and how to restructure and change the growth pattern.

(2) The massive population has come into sharp conflicts with the availability of natural resources. With the transition in demographic structure, the problems have become more and more acute as to how to raise the general quality of the population, relieve the pressure of the aging population and provide more jobs. The task of eliminating poverty remains arduous even China has made great progress in the field.

(3) The situation is stern in the demand and supply of such strategic resources as petroleum, natural gas, water, land and major minerals, etc. The dependency on the import of oil and gas and other resources has been rising steadily, presenting increasingly serious problems of sustainable utilization of resources and resources security, which are likely to threaten gravely the social and economic development and sustainability.

(4) We are facing the complex, trans-boundary environmental pollution issues that are different from the traditional ones and hard to cope with; the regional air pollution and river basin water pollution are becoming more and more serious with each passing day.

(5) A growing number of evidence shows that the greenhouse gases generated by human activities are causing global warming that will bring about a series of systemic changes, thus exacerbating the risks. As the second largest country with regard to greenhouse gas emission, China is facing a tremendous pressure from the international community with regard to emission reduction, which is likely to retard the progress of modernization.

(6) China has not paid enough attention to sustainable development of cities. The high-speed urbanization, increasingly expanding consumerism and the negligence or ignorance of the environmental and resource problems in city construction will narrow the space for realizing sustainable urbanization.

(7) As all government departments, enterprises, civil organizations and other interest groups are being diversified, they have become stronger in expressing their appeal, bringing about all kinds of contradictions and even conflicts. However, the interests of vulnerable groups and disadvantageous regions are often ignored. Improving the governance of sustainable development are receiving more attention.

The scientific approach to development and the principle of building a harmonious society, the enhancement of the economic and science and technology strength, the mainstreaming of resources conservation and environmental protection-all have become an indispensable part for changing the development pattern and promoting national economic and social development. Specifically, the energy conservation and emission reduction targets and the plan of action to cope with climatic changes set in the '11th Five-Year Plan (2006-2010)' have brought about real opportunities for realizing sustainable development. A number of institutional arrangements have been set up for achieving the mandatory targets. In the past five years, China made genuine progress in energy conservation and emissions reduction. Energy consumption per unit GDP fell by $19.1 \%$, chemical oxygen demand by $12.45 \%$ and sulfur dioxide emissions by $14.29 \%$.

\section{China's Sustainable Development Policies in Retrospect: Experience and Lessons}

It takes a process of learning to formulate policies and 
improving institutional development. As the resource and environment issues are becoming increasingly complicated and constantly changing and we are still not very clear about the law governing sustainable development, we have to learn from the past experience and lessons in improving the policies related to sustainable development, identify problems in policy implementation and, by constant practice and summing up, chart the course for future policy development.

\subsection{Major changes in sustainable development policies}

Looking back, it is already more than 30 years since China had its policies concerning population, resources and environment. The development of these policies is also a process of transition from planned economy to a market economy and a change from satisfying the basic needs to sustainable development. But the real major change comes from the introduction of the concept of sustainable development. Starting from the late 1990s, with the growth of the economic strength and the strong retaliation by nature for our improper development behavior, we have been undergoing fundamental changes in our knowledge of resources and environmental protection, line of thinking in pollution control and development strategy in the general context of reform and opening up and the across-the-board transition. The major changes over the past decade in the area of sustainable development are as the follows:

(1) A change from population control to human resources development (China Education and Human Resources Project Group, 2003).

(2) A change from engineering water conservancy to resources water conservancy, modern water conservancy and sustainable development water conservancy (Wang, 2005).

(3) A change from timber-oriented production to ecology-oriented construction (Zhou, 2001), with the 'National Ecological and Environmental Construction Program' and 'National Outlined Program for the Protection of the Ecology and Environment' being formulated and a series of the most important yet ecological protection and restoration projects being started.

(4) Three historic transitions in environmental protection: 1) Transition from ignoring environmental protection in the singular pursuit for economic growth to strengthening environmental protection and optimizing economic growth, making environment management as a major means to promote economic restructuring and change economic growth pattern; 2) change from environmental protection lagging behind economic growth to synchronizing environmental protection and economic development; and 3) transition from protecting the environment mainly by administrative means to resolving environmental problems by the combination of legal, economic and technical means, plus administrative means, if necessary (Wen, 2006).

(5) Transition from traditional industrialization to a new type of industrialization, striving to give full scope to the development of products with a high technical content, good economic benefit, low resources consumption and less environmental pollution and to the advantage of human resources (Jiang, 2002).

(6) Putting forward the 'people-oriented' principle and the approach of comprehensive, harmonious and sustainable scientific development (Report to the Third Plenary Session the 16th Central Committee of the Communist Party of China), making energy conservation and emission reduction the binding targets that must be realized in the '11th Five-Year Plan' so as to build an resource-efficient and environment-friendly society.

\subsection{Problems of sustainable development policies}

Despite the great achievements in sustainable development, there are still some problems that can not be ignored and need to be addressed through greater efforts in the future, and the problems contain the following major aspects.

(1) There is a weakening in the abilities of overall coordination abilities in environmental protection and sustainable development. Before 1998, the former Environmental Protection Committee of the State Council played a big role in coordinating the efforts of all departments in environmental protection. But, with the reorganization of the State Council, the committee was dismissed. Furthermore, the functions of environmental protection of the industrial departments had been delegated to various industrial associations due to the cancellation of those government departments, thus weakening the work on environmental protection. The ministerial joint meeting system of the State Council is hard to play its due role due to the limited status of the State Environmental Protection Administration.

(2) Though advanced the idea of new type of indus- 
trialization is, there is no successful experience and operable model to go by. As a big economy, it is hard to alienate itself from the general law governing industrialization. Although there is the advantage as a late comer, it is hard to leap over the process of developing heavy and chemical industries. The new type of industrialization lacks specific path guidance and effective transfer of sustainable technologies from developed countries. It is, therefore, not easy to restructure the economy, change the development pattern, and evolve a sustainable production model.

(3) We have not decided what path to follow toward sustainable urbanization. We do not have effective supervision and management means and assessment indictors in city construction and development; there is no demand and supply management policy; local protectionism, the stubborn pursuit for GDP growth, and seeking things big, high and new are prevailing; and fail to mainstream resources and environmental protection in city development - all of these have resulted in the lagging of the construction of urban environmental infrastructure. The newly added industrial capacities, energy-consuming city facilities and excessive consumption demand will become new pressures on resources and environment.

(4) We have adopted two different policy approaches with regard to energy conservation and emission reduction. In the area of energy conservation, we have adopted the efficiency indicators in conformity with the strategy of decoupling economic growth and material consumption, marked by high resource productivity; but in the area of emission reduction, we have employed the total amount indicators, which have to be paid at a high price for a developing country that has not reached the mature stage of economic growth. Under the condition in which the environment for policy implementation is not sound and institutions are lacking, it merits further exploration as to what emission reduction policy is more cost effective.

(5) Many of our current policies lack the backing of sound basic data and information and solid scientific study. The process of setting policy goals is too simplistic, lacking real independent argumentation system and reasonable procedures, unable to make the limited amount of funds serve the purpose of realizing priority policy goals. For instance, the current principal pollutants cannot reflect the real situation of composite pollu- tion and we are still not very clear about the non-point pollution which accounts for an increasingly big share of the total pollution, thus making the real effect of emission policy goal greatly discounted. Besides, evidences show that the consumption of energy and major minerals and pollution discharge are far from arriving at the downward inflexion point of the total growth. Any radical policy without the support of scientific data will have limited results, thus leaving in the end a growingly long list of problems to be tackled.

(6) The general design of ecological protection and construction projects over the past ten years conforms to the general orientation toward sustainable development. But, the absence of long-term plan, too high a subsidy standard and narrow departmentalism have resulted in undue expansion of 'grain for green' project, so much so that it has simply been reduced to unitary afforestation project. In addition, the overlapping of project management organizations has also added to the management cost and reduced the policy efficiency. Besides, the ecological restoration has not been well integrated with the long-term alternative means of subsistence of farmers. At the end of projects, the risks of disafforestation and land reclamation have remained, thus reducing the effectiveness and sustainability of projects and policies.

(7) There is a lack of basic institutional arrangements and policy guarantee for realizing sustainable development and building a resource efficient society. This is mainly manifested in the unsound property right system, pricing mechanism and economic incentive policies, thus unable to provide the motive force for saving resources and reducing emission. Neither is it possible to effectively encourage technical innovation. Some of the policy means (especially part of the market-based means) still lack the preconditions for effective implementation.

(8) It is different from the series of sustainable development problems in transition that the corresponding laws, management systems and policy means are still lagging. The asymmetry between the trans-sectoral and trans-administrative regional nature of resource and environment problems and the administrative jurisdictions, as well as the incomplete governance structure have made it hard for the existing institutional arrangements and policy measures to play their roles effectively, thus unable to revolve the above complicated systemic problems. The future sustainable development policies also need transition at the same time. 
In a certain sense, sustainable development is not merely a technical issue, but rather, in the first place, a matter of governance. Solution to the governance issue requires the change in management thinking, prioritizing the reform of management system, institutional building and innovation, and the mutually supportive comprehensive policy means, strengthening effective coordination and cooperation among different sectors, administrative regions, and stakeholders, and giving full scope to the functions and roles of all stakeholders. Good governance is highly associated with the insurance of resource security and improvement of environmental quality. Effective institutional arrangements, comprehensive policy options, and incremental policy goals provide the basic guarantee for simultaneously realizing economic growth and improving resource and environment performance.

\section{Policy Approach and Priority Actions}

In order to accomplish the objectives and tasks set for sustainable development, we need to strengthen the leadership and coordination of various government departments, foster broader cooperative partnership for promoting sustainable development and, on the basis of summing up historical experience and from a long-term objective view, pay attention to institutional building, improve the policy implementation environment, raise policy efficiency, strengthen resource and environment management, and adopt effective priority actions to overcome difficulties and bring the modernization onto the orbit of a benign cycle. The followings are the recommendations and priority actions with regard to reform and development in laws and regulations, management organizations, policy means and public participation related to sustainable development.

\subsection{Improve legal system for sustainable develop- ment}

The principles of sustainable development should become the basic principles for making and amending laws and regulations. At present, there are conflicts and contradictions among the laws and regulations for sustainable development, lacking comprehensiveness, coordination and unified management. The participation and the responsibilities and obligations of all stakeholders are not clearly defined. It needs in-depth study, taking into consideration of corresponding laws.

(1) To give an overall consideration to the amendment of laws and regulations. At present, in view of such outstanding problems as the tendency of department dominating law making, the lack of coherence and complementarity among different laws and regulations, lack of trans-sectoral and trans-regional management rules, inadequacy of procedural legislation, and laxness in law enforcement (Wang et al., 2007), it is necessary to adjust the current laws and regulations under the framework of sustainable development to make them adapt to the comprehensive requirements of sustainable development so as to resolve the difficulty in trans-sectoral and trans-regional sustainable development.

(2) To add the provisions on stakeholders in the laws. There are still no legal provisions on stakeholders of sustainable development. The contents to be added to laws should include departmental coordination mechanisms, functions and responsibilities of stakeholders (including government departments) in ecological compensation, the procedure of public participation, information disclosure system, the procedure for identifying pollution accidents and settlement procedures.

(3) To clearly define the responsibilities of management departments in sustainable development. For instance, the functions and responsibilities are not clearly defined among environmental protection departments, water resources departments, watershed management organizations and other related government organs in the management of watershed water environment. This has made it difficult to carry out related work. The related laws should be amended to clarify the functions and responsibilities of each government departments.

\subsection{Set up comprehensive management organiza- tions in related areas of sustainable development}

Organizational reform is one of the core contents of sustainable development. Without rational management mechanism, it is impossible to realize sustainable development. At present, such government functions in energy, environmental protection and communications associated with sustainable development are dispersed among different government departments, industrial associations and even state-owned enterprises. There is a lack of coordination mechanism among stakeholders, resulting in half the results with double the efforts. It is, therefore, necessary to have the unified and comprehen- 
sive management departments in related areas. Exercising comprehensive management does not necessarily mean centralizing power in a single government department. It simply means to unify the management functions dispersed among different departments and give full scope to the advantage of central authorities in resolving pressing problems in sustainable development, and at the same time to form a good governance structure, make policy decision making more scientific, democratic and institutionalized, display effectively the functions of the unified management department, set up coordination and cooperation mechanism among different departments, gradually intensify the participation of all stakeholders and better realize the objectives of sustainable development.

The organizational reform of government touches many aspects and it requires the integration of long-term and short-term interests and the relations between the whole country and localities. It is, therefore, necessary to advance the reform in the step-by-step manner taking into account the differences of different management areas and accumulating experiences by undertaking reform on the pilot basis.

(1) To give priority to the establishment of 'big department system' on the pilot basis in such core areas of sustainable development as energy, environmental protection and communications, merging the governmental functions dispersed in different departments in order to resolve the problems of function overlap, management duplication and low efficiency in administrative work. At the same time, it is necessary to set up a unified supervision and management mechanism, coordination mechanism, integrated policy making mechanism and public participation mechanism to ensure the normal operation of the management system and the realization of objectives, thus manifesting the unity, comprehensiveness and coordinative nature of the work of sustainable development so as to realize the priority objectives in energy conservation, emission reduction, in coping with climatic changes and the shifting of development pattern (Wang, 2006).

(2) To complete the comprehensive coordination mechanism at the national level. Due to limitations in nature, status and authorities, neither the inter-ministerial joint meeting system nor the leading group for sustainable development strategy can undertake the high-level coordination regarding sustainable development. Even the proposed comprehensive administrative departments of energy, environmental protection and communications do not have the ability of coordinating different departments. It is, therefore, necessary to set up a comprehensive coordination mechanism at the State Council level.

\subsection{Improve coherence of sustainable development policies and exert role of policy portfolio}

(1) To make 'low carbon development' an important part of sustainable development and build a resourceefficient and environment-friendly society with low emission of carbon dioxide. The challenges brought about by climatic changes cover all areas and it has become one of the development orientations to develop a low carbon economy. But such development path involves complicated policy objectives. It requires a cautious attitude, comprehensive studies and a trade-off of different policy objectives concerning development and climatic changes, making proper choices and acquiring practical knowledge from the government policy formulation and actions of enterprises so as to enable the strategic adjustment to have a great positive impact.

(2) In order to display the role of policy portfolio and prevent different departments from making their own policies, we should conduct a comprehensive assessment of the existing policies and their implementation environment and analyze the advantages, disadvantages and preconditions of different policies from a long-term point of view, carefully sum up successful experience and lessons from failure and handle well the relations among growth, environmental protection, employment, alternative means of subsistence and enterprise competition, get clear about policy objectives, reduce repetitiveness of policies and adopt the most cost-effective and operational economic incentives.

(3) To implement the integrated watershed management on the pilot or demonstration basis. The integrated watershed management is an import policy measure for addressing the resource and environmental issues in river basins and balancing the objectives for watershed economic development and ecological conservation. It requires a management framework based on legislation, planning and policies and according to actual situations of the localities. It also requires timely summing up and spreading of the successful experience in integrated watershed management through pilot or demonstration im- 
plementation.

(4) To improve the information system and set up a comprehensive information platform. The basic information for sustainable development is the basis for formulating policies. The basic state of resources and environment can be acquired through information monitoring, system assessment and corresponding research thus helping us see the risks and uncertainties so as to provide the scientific basis for seeking solutions to problems and for formulating policies.

\subsection{Improve governance structure and promote public participation}

Public participation is of great significance in environmental protection and sustainable development. China has its particularities in promoting the public participation in the process of policy making and decision making on sustainable development. It has to proceed from multiple levels and take actions in a gradual manner. It is recommended to do the following work well:

(1) The rights and interests of civil organizations, citizens, and other non-governmental entities in participating in the management related to sustainable development should be further provided by relevant legislations and the specific procedural provisions should be established for that purpose.

(2) To actively encourage the environmental public interest litigation. Any citizen and social group may take legal action against any management organ for failure to perform legal responsibilities or any entity or individual that pollutes the environment or damages the environment, and the reversion of burden of proof should be adopted.

(3) Support the development of National Geographic Organizations (NGOs) by multiple means. For instance, related laws should be revised to make easier the registration of NGOs; relevant laws concerning tax exemption for donations should be made so as to encourage Chinese enterprises and individuals to donate to NGOs. Attention should be paid to the capacity building of NGOs.

(4) To extend the public right to know. This requires the openness of administrative affairs and the introduction of the public announcement system with regard to environmental policies and laws, project examination and approval and case handling. It also requires the improvement of government websites and publishing of information about environment quality and environmental management to keep the public and NGOs well informed on resources and environment management, decision making, and the implementation of plans. To make enterprises disclose environmental information according to laws, e.g., making the list of toxic materials used be available to the public.

(5) To give full scope to the media in supervising related management departments over their administration according to law and enterprises over their environmental behaviors. To intensify the publicity about the importance of public participation and enhance the initiatives and stewardship of the public in participating in the affairs concerning resources and environmental management, thus creating pressures and driving force for the cooperation among stakeholders.

\section{Conclusions}

Since 1992, China has made great progress in various fields of pursuing sustainable development including institutional arrangements, policy making, technological advance, taking concrete and comprehensive actions. Entering the 21st century, China is facing a series of development challenges under a new global context. As a great emerging economy, China has to explore its own development path and there is no ready formula. During the 11th Five-Year Plan period (2006-2010), China gradually mainstreamed the energy conservation and pollution reduction into economic restructuring process by adopting an integrated and mandatory approach. By reviewing China's development in the past 20 years, experience and lessons are coexisting for sustainable growth. In the 12th Five-Year Plan period, Chinese government will continue the approach and mainstream the transformation of economic development pattern for a green and low carbon future. China's practice for sustainable development will be beneficial for both itself and other countries.

\section{References}

AASA (The Association of Academies of Sciences in Asia), 2011. Towards a Sustainable Asia: Green Transition and Innovation. Beijing: Science Press and Springer.

China Education and Human Resources Project Group, 2003. From a Big Power in Population to a Strong Power in Human Resources. Beijing: The Higher Education Press. (in Chinese) 
Compilation Group of the People's Republic of China National Report on Sustainable Development, 2002. The People's Republic of China National Report on Sustainable Development. Beijing: China Environmental Science Press. (in Chinese)

Connor R, Dovers S, 2004. Institutional Change for Sustainable Development. Cheltenham: Edward Elgar Publishing.

European Commission, 2007. 2006 Environmental Policy Review. Luxembourg: Office for Official Publications of the European Communities.

Jiang Zemin, 2002. Build a Well-off Society in an All-round Manner and Break New Ground in the Cause of Building Socialism with Chinese Characteristics, Report to the 16th $\mathrm{Na}$ tional Congress of the Communist Party of China. Available at: http://www.china.org.cn/chinese/2002/Nov/233867.htm. (in Chinese)

Sustainable Development Strategy Research Group of the Chinese Academy of Sciences, 2006. China Sustainable Development Strategy Report 2006-Building a Resource-Efficient and Environment-Friendly Society. Beijing: Science Press. (in Chinese)

Sustainable Development Strategy Research Group of the Chinese Academy of Sciences, 2008. China Sustainable Development Strategy Report 2008-Policy Review and Outlook. Beijing: Science Press. (in Chinese)

Sustainable Development Strategy Research Group of the Chinese Academy of Sciences, 2009. China Sustainable Development Strategy Report 2009—China's Approach towards a Low Carbon Future. Beijing: Science Press. (in Chinese)

Sustainable Development Strategy Research Group of the Chinese Academy of Sciences, 2010. China Sustainable Development Strategy Report 2010-Green Development and Innovation. Beijing: Science Press. (in Chinese)

Sustainable Development Strategy Research Group of the Chinese Academy of Sciences, 2011. China Sustainable Development Strategy Report 2011-Greening the Economic Transformation. Beijing: Science Press. (in Chinese)
The State Council of the People's Republic of China, 2006. The 11th Five-Year Plan for National Economic and Social Development of the People's Republic of China. Available at: http://news.xinhuanet.com/misc/2006-03/16/content_4309517. htm. (in Chinese)

UN (United Nations), 2009. The Millennium Development Goals Report 2009. New York: United Nations.

UNEP (United Nations Environment Programme), 2007. GEO-4. UNEP

Victor D G, 2006. Recovering sustainable development. Foreign Affairs, 85(1): 91-103.

Wang Shucheng, 2005. Water Conservancy as Resource, Harmony between Man and Nature. Beijing: China Water Conservancy and Hydropower Publishing House. (in Chinese)

Wang Y, 2006. China's environment and development issues in transition. Social Research, 73(1): 277-291.

Wang Y, Li L F, Wang X J et al., 2007. Taking Stock of Integrated River Basin Management in China. Beijing: Science Press.

WCED (The World Commission on Environment and Development), 1987. Our Common Future. Oxford: Oxford University Press.

Wen Jiabao, 2006. Implement the Scientific Development Approach and Accelerate the Pace of Building An Environmentfriendly Society. The 6th National Environmental Protection Conference. Available at: http://www.gov.cn/ldhd/2006-04/23/ content_261716.htm. (in Chinese)

World Bank, 2003. World Development Report 2003. Washington, DC: World Bank.

WSSD (The World Summit on Sustainable Development), 2002. Johannesburg Plan of Implementation of the World Summit on Sustainable Development. UN. Available at: http://www.un.org/ esa/sustdev/documents/WSSD_POI_PD/English/POIToc.htm.

Zhou Shengxian, 2001. Historical Change in China's Forestry Industry. Beijing: China Forestry Publishing House. (in Chinese) 